\title{
Suspending Syntax: Bodily Strain and Progressivity in Talk
}

\author{
Emily Hofstetter*, Leelo Keevallik and Agnes Löfgren \\ Department of Culture and Society, Linköping University, Linköping, Sweden
}

People speak not only under relaxed conditions but also during strenuous activities, and grammatical resources can be used to achieve displays of strain. This study looks at the relationship between progressivity of talk and bodily strain, focusing on the practice of temporarily suspending syntax while the speaker is accomplishing a physically challenging task. Based on examples from two different physical activities, rock climbing and opera rehearsals, the paper argues that the practice of suspending syntax is a resource available across contexts to render prominence to the strained body and highlight ongoing movement or other bodily action. By placing the strain-based display of incapacity to talk at a moment when the emerging syntactic structure is incomplete, participants maintain rights to resume talk while also presenting themselves as possessing the physical capacity to do so. Suspending syntax is shown to be a minutely timed speakers' technique that takes advantage of the emergent nature of syntax and that demonstrates how speakers organize language in relation to the sensing and moving body.

Edited by:

Junying Liang,

Zhejiang University, China

Reviewed by:

Marina N. Cantarutti,

The Open University

(United Kingdom), United Kingdom

Rein Ove Sikveland,

Norwegian University of Science and

Technology, Norway.

*Correspondence:

Emily Hofstetter

emily.hofstetter@liu.se

Specialty section: This article was submitted to

Language Sciences,

a section of the journal

Frontiers in Communication

Received: 02 February 2021

Accepted: 05 May 2021

Published: 21 July 2021

Citation:

Hofstetter E, Keevallik L and Löfgren A (2021) Suspending Syntax: Bodily

Strain and Progressivity in Talk.

Front. Commun. 6:663307.

doi: 10.3389/fcomm.2021.663307
Keywords: syntax and grammar, bodily strain, emergent grammar, multisensoriality, multimodal interactional analysis

\section{INTRODUCTION}

Syntax emerges in the course of speaker turns in interaction (Auer and Pfänder, 2011; Pekarek Doehler et al., 2020), and syntactic structures are regularly accomplished in the interplay of multimodal resources, including language, gaze, gesture, and mobility (Broth and Mondada, 2013; C. Goodwin, 1979). Notably, the body is a central resource for managing emergent syntax, among other phenomena, which Keevallik (2018) has called the grammar-body interface. The real-time nature of spoken language and interaction centrally involves progressivity-the participant orientation of moving to next matters, including syllables, words, turnconstructional units (Schegloff, 2007, pp. 14-15), and embodied motions (Keevallik, 2013b)-which makes possible the temporal organization of grammar and bodily involvements for meaning-making and intersubjectivity. A corollary of a relationship between grammar and body is that they mutually activate each other in any moment of language use. This study examines a practice that demonstrates precisely this mutual activation of body and grammar: the practice of suspending syntax at moments of bodily strain. Participants take advantage of the relationship between body and syntax to display a bodily event through systematic, emergent grammatical patterns. The following extract illustrates the practice of syntactic suspension. Quin is rock climbing and is about to attempt a challenging move. As Quin lifts his left foot, he briefly halts his in-progress clause (line 3). After a silence, Quin resumes the clause, blending a strain vocalization (the uvular trill [R]) into the start of the next word, much. 


\section{Extract 1 | KY190731 Creature Feature _3:50.}

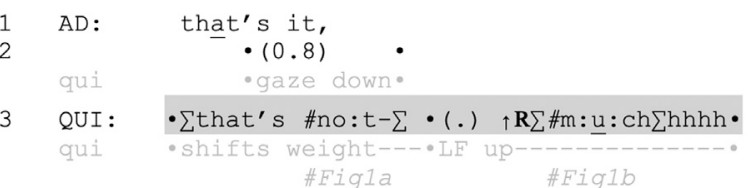

The suspended syntax suggests a temporary incapacity to continue uttering the clause, and therein displays intense bodily strain. The suspension occurs as Quin visibly enters a physically difficult motion: he needs to balance himself on only one foot while vigorously pushing himself upward along the wall (see Figure 1). The suspension of syntax is timed to co-occur with a physical effort. By suspending syntax, Quin displays himself as temporarily hindered from producing simultaneous speech and bodily movement. The sounds are squeezed out in strained voice, then temporarily halted entirely, possibly as a physiological corollary of establishing tension in the torso muscles (Hodges et al., 2005; Hagins and Lamberg, 2006; Massery et al., 2013). Furthermore, the timing of the strain display ties the utterance to the move at hand and makes the assessment of the handhold (not much, i.e., it is too small for the climber to hang on) relevant to the current motion, since balancing on one foot is harder with a poor handhold. Quin also achieves a display of barely maintained control, in first launching the syntactic structure while under strain and then persisting with the clause, completing it as initiated. In summary, syntactic suspensions displays a specific form of strain, one that straddles being in control and being too strained to continue. It (re)produces the body as an interwoven component of emergent syntax.

In this paper, we will examine syntactic suspensions in moments of bodily strain. We will describe the work participants undertake to achieve the suspension, through syntax, prosody, and bodily engagement. We will also show that it is a sufficiently established practice to even be used as a conventionalized display of strain. Throughout the paper, we suggest that it is not possible to disentangle the ontology of human syntactic suspensions; for participants they are both a consequence of bodily activation and a designed and accountable linguistic phenomenon. A controlled body is implicit in the production of "through-produced" syntax, while body under strain can accordingly be displayed through disruptions to syntax. This paper highlights how participants organize and take advantage of this connection.

\section{Syntax and the Body}

Several prevailing conceptions of syntax have placed it entirely within the mental realm, arguing that it is an autonomous system of abstract rules. This definition has excluded the bodily production of speaking from the domain of syntactic analysis and fails to adequately address the role of syntax in embodied interaction. The so-called written language bias in linguistic theories (Linell, 2005) has furthermore resulted in the omission of not only the body, but the situated emergence of syntax together with the body in everyday talk. Previous studies that investigate the connection between the body and language have largely treated language as

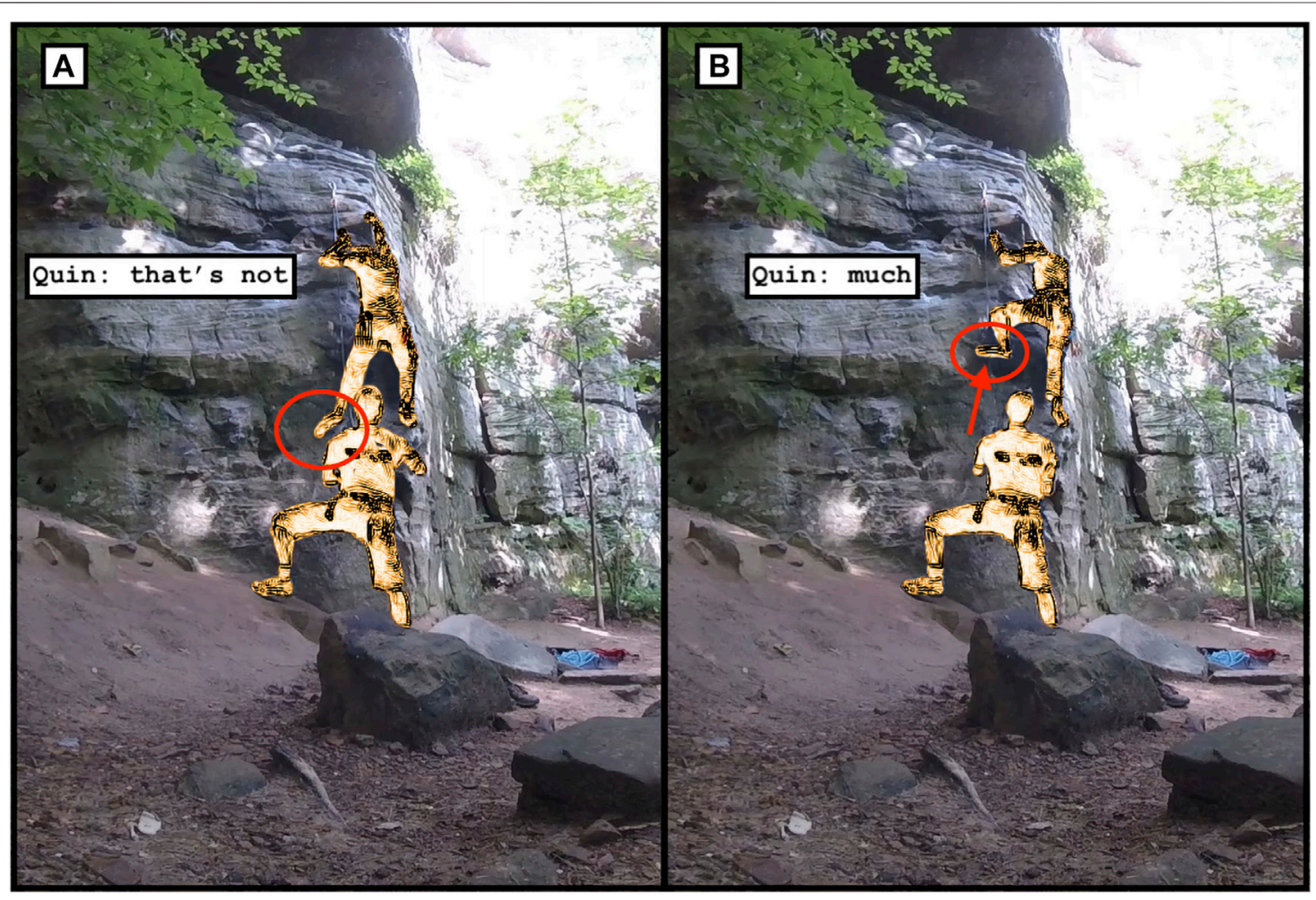

FIGURE 1 | Quin begins the clause before lifting his leg and foot, and continues it when his leg reaches hip height (when his abdomen must engage more strongly to keep lifting the leg and foot). 
individual and non-interactionally situated (an early example being Lakoff and Johnson, 1980).

These studies assume that grammar is a self-contained, mental pattern highly abstracted from existing or imaginary sentences and independent of actual use (e.g. Evans, 2006; Radford et al., 2009). As a result, any given language's grammar is treated as a consistent, predefined structure, and deviations as irrelevant chaos or poor performance (e.g. Chomsky, 1965; Newmeyer, 2003). In contrast, studies of situated language use have not only found new and highly organized practices for managing syntax in everyday activities (and this paper reports another such practice), they have also presented cross-linguistic evidence that grammar, including syntax, is a temporally unfolding resource for interaction (e.g. Hopper, 1987, 2011; Hakulinen, 2001; Auer, 2009; Linell, 2009; Fox and Thompson, 2010; Pekarek Doehler et al., 2015). In resituating syntax in its natural ecology, which, after all, is language's most common site of occurrence, and its evolutionary niche (Bögels et al., 2020), these paradigms have been able to show how language interacts with other semiotic resources, such as prosody, gaze, gesture, and the moving body (e.g. C. Goodwin, 2018; Hayashi, 2005; Keevallik, 2013b, Keevallik, 2018; Mondada, 2014). This paper continues the quest of resituating syntax in the living world and living body, by focusing on progressivity within clauses.

Clauses are one of the central resources that syntax structures and they also constitute core units for turn taking in interaction in several languages (Helasvuo, 2001; Thompson and Couper-Kuhlen, 2005). Clauses are neither pre-established in terms of an exclusive set of fully specified patterns, nor are they necessarily fully pre-arranged in the minds of speakers before an utterance is "sent". Instead, clauses are emergent over the course of time, dependent on other participants actions and creating possible moments of turn-completion for next speakers to be able to take their turn (Schegloff, 1996). Clauses have also been shown to emerge in close coordination with bodily action. Goodwin (1979) provided a famous example in English that demonstrated how an utterance need not be produced as a single, independent, coherent proposition, but may emerge incrementally in reaction to gaze by different participants. In a similar vein, Iwasaki $(2009,2011)$ has shown how clausal turns in Japanese emerge as a result of dynamic interactive processes, which include "interactive turn spaces"-places where the speaker of the unit-in-progress invites the interlocutors to co-participate in the building of the action.

Alternatively, a speaker may abandon a turn-in-progress as soon as the action has been treated as complete through the recipient's bodily visual response (Ford et al., 2012, p. 206; see also $\mathrm{Li}, 2016)$. The body can even complete verbal clauses, as if filling in the silent slots left after incomplete syntax (Keevallik, 2013b). Verbal syntax can be discontinued for an embodied demonstration after verbs, copulas and quotatives, but also adverbial phrases, adjectives, articles and subjects (Keevallik, 2015). These embodied displays effectively take the position of lexical units; not only do language and gesture complement each other when making meaning in so-called composite utterances (Enfield, 2009), but an embodied demonstration can actually occupy a grammatical and temporal slot within the emerging syntax (Keevallik, 2013a). It has, for example, been shown that a speaker can complete a grammatically incomplete structure with an explanatory gesture, such as in word searches (Hayashi, 2003) and in second language conversation (Olsher, 2004; Mori and Hayashi, 2006). Slots for embodied displays can also be projected by specific phrases, such as und ich so/und er so "and I'm like/and he's like" in German (Golato, 2000) and it's like in English (Fox and Robles, 2010). The slots filled by bodily displays even function similarly to verbal turn components (Ford et al., 2012; Keevallik, 2018), suggesting a strong emic basis for incorporating these bodily options in a descriptive grammar. In short, we have begun to see how various aspects of embodied behavior participate in and steer emergent grammar.

Given that syntax is dependent upon a living body in order to be expressed (from airflow in speaking, to motions for typing, signing, or machine-assisted talk), it is remarkable that so little work has addressed the connection between the situated living body and syntax in interaction. This paper will target that gap, focusing on scenarios where bodily involvements are made relevant for syntax production, and where the connection between syntax and body becomes a member's resource for a particular action through the phenomenon of strain.

\section{Managing Syntactic Progressivity}

Progressivity is a central concern for participants, both regarding the advancement of interpersonal interactional sequences as well as internal components of individual speaker turns (Schegloff, 2007, pp. 14-15). Nevertheless, disruptions ${ }^{1}$ to syntactic progressivity occur in many different scenarios in interaction; parenthetical clauses, word searches, self-repair, certain question formats, and collaborative completions all exploit the normatively through-produced nature of syntax, and are dealt with in systematic ways by the interacting parties. For example, parenthetical clauses can be inserted into clauses that were already in progress and projected to be complete, which results in temporarily halting, then resuming, the parent clause's syntax (Mazeland, 2007). This "enables a speaker to reconcile the potentially contradictory requirements that the linearity of speech production poses to the speaker's orientation to recipient design" (Mazeland, 2007, p. 1816). Word searches, a type of self-repair, constitute another instance of compromising progressivity, as they are also initiated by a disruption in the utterance, resulting in a delay in the middle of an ongoing turn-constructional unit (TCU) (M. H. Goodwin and Goodwin, 1986; Hayashi and Yoon, 2006). In this paper, we are likewise focusing on structures that involve the process of suspending a clause that was projected to be complete, rather than just any word combinations. While mid-TCU silences have mostly been connected to cognitive trouble, such as in word

\footnotetext{
${ }^{1}$ We use the term "disruption" or "disrupted" to refer generally to any kind of discontinuation or trouble with continuing a clause (e.g. repair, abandonment, etc.). 'Suspension' is restricted to the phenomenon in this paper, where a clause is initiated, temporarily halted, and resumed. In other words, we treat "disruption" as the umbrella term, and "suspension" as a type of disruption, specific to the phenomenon in this paper.
} 
searches, we will argue that they can also be related to bodily concerns.

Mostly, disrupted syntactic structures (including those lacking embodied completion) are treated as inadequate for achieving a complete turn-at-talk. Where speakers do leave a phrase incomplete, it is marked; it does something in the interaction. Leaving an utterance entirely unfinished can be a way to leave something delicate unspoken, inviting co-participants either to produce a completion of the item (such as in bad news deliveries, Lerner, 2003) or to align by treating the unfinished phrase as adequate for progressing the sequence (as discussed in Chevalier and Clift, 2008). Disrupted syntax is one way to designedly invite collaborative completion or "recipient intervention" (Lerner, 2013, p. 125). One format, "fill-in-the-blank" questions (Persson, 2017), is often used in institutional environments such as teaching (Koshik, 2002). Collaborative completions may take advantage of compound TCUs underway to complete the syntax and thereby demonstrate affiliation, agency or epistemic rights, through co-authorship of the statement: the collaborator in this case "co-authorize[s] what is being done" (Lerner, 2003, 2013, p. 126). However, the practice described in this paper involves a more abrupt suspension of syntax, often through cut-offs, which is more commonly used for initiating self-repair (Fox et al., 2009). Furthermore, in self-repair, speakers often reframe the repair solution in a way that backtracks to a prior noun, verb, or prepositional phrase (Schegloff, 1987; Fox et al., 2009), thus restarting the syntax. This provides recipients with the needed resources to determine whether the talk following a disruption is, indeed, a repair of the prior talk, or a continuation of it (Sidnell, 2006a). In moments of repair, by reframing the post-disruption talk to re-start the syntax, speakers can situate the trouble solution with respect to the original phrase.

As we will show below, such reframing is rare in our suspensions; they often begin where they left off, so to speak, unless competing talk forces them to re-attempt a suspension (see Interactional Treatment of the Practice as Coherent). With these considerations in mind, we can define this paper's phenomenon more specifically: a syntactic suspension is a moment when an initiated clause (projected to have complete clausal components) is temporarily halted, resulting in a silence, before being resumed, at least briefly, along one of the potential clausal continuations that was projectable before the suspension began (see Methods for further details). We will show how the practice of syntactic suspensions connects the progressivity of a clause to a developing embodied activity. The study will thereby further inform our understandings of how participants orient to both syntax and the body as reflexively constituted social phenomena.

\section{The Bodily Foundation of Speaking}

People use their bodies for both physical movements and speaking. Speech is produced through the same anatomical structures that ensure the maintenance of life through breathing: the lungs, the larynx, and the vocal tract. Muscles of the breathing and vocal apparatus control whether air can pass through the glottis. With respect to breath tasks relevant to this paper, these muscles must manage breath holds, glottal closures, as well as participate in maintaining sufficient air pressure for speech (Lieberman and Blumstein, 1988; Hixon et al., 2018; Fuchs and Rochet-Capellan, 2020). Strenuous activities alter speech breathing and speech production, as the body's need for oxygen increases, resulting in additional physical effort should one want to speak, as well as perceivable, effort in the voice (Sandage et al., 2013; Trouvain and Truong, 2015). Even with strain, however, speakers are often able to constrain breathing to occur at syntactic boundaries (Trouvain and Truong, 2015; Hixon et al., 2018), which maintains the coherency of the emerging syntax.

Many of the same muscles used for breathing are implicated in establishing certain forms of bodily stamina, tension, and steadiness. Physiologically the human body has more stamina when the torso and breathing muscles are engaged, including laryngeal muscles that close the glottis (Hodges et al., 2005), as is sometimes the case during breath holds (Massery et al., 2013) or controlled/forced exhalation (Ikeda et al., 2009; O'Connell et al., 2016). When these muscles or breathing techniques are used, the body can undertake more force or exert strength longer (Welch and Tschampl, 2012). Even untrained people spontaneously hold and control their breath when lifting objects (Mateika and Gordon, 2000; Lamberg et al., 2003; Hagins and Lamberg, 2006). Since breath and muscle tension are necessary for language production, when these systems are bound up in other activities, a speaker may face trouble in producing normal speech. As we will show below, however, such difficulties may actually provide affordances for displaying strain.

\section{Syntactic Disruptions as a Sign of Bodily Concerns}

As the above prior research demonstrates, incomplete syntax is taken as a sign of some trouble on the part of the speaker (from finding an appropriate word to having sufficient breath), and coparticipants either withhold talk until progressivity is resumed or provide assistance to progress past the trouble. Sometimes the disruption arises due to communicative deficits. In the utterances of people with aphasia and other communicative disorders, turns are characterized by multiple silences that punctuate the TCU at inapposite moments (Laakso and Klippi, 1999). Stammering creates disruptions on the phonemic, syllabic or word level (R. Wilkinson and Morris, 2020), while anomia and agrammatism may occasion perturbations due to inability to produce the next relevant word, and dysarthria may lead to frequent repair (Auer et al., 2020). Progressivity halts in these interactions often make the turns of persons with communicative deficits vulnerable to completions by other interactants. Whether such collaborative completions are an intrusion or a resource is unclear (Aaltonen and Laakso, 2011; Norén et al., 2013). "Intrusions" can permit speakers to progress the interaction more smoothly (C. Goodwin, 1995; Perkins, 2003) with the result that "the attention to the aphasia is minimized" (Oelschlaeger and Damico, 1998; Bloch and Beeke, 2008).

The syntactic suspensions in the current paper are attributable to bodily strain and the body being given prominence and precedence over speech (i.e., the bodily activity is progressed 
even if speech is delayed, much like in some cases of multiactivity, Haddington et al., 2014). The focus of study here is not bodily deficits or disability-related speech disruption and, to the contrary, we will show that participants go to some work to demonstrate (partially maintained) control over the timing of the suspension and resumption of their talk (What's in a suspension?, Interactional Treatment of the Practice as Coherent).

In short, research on atypical interaction demonstrates how incomplete syntax is treated as accountable and possibly a sign of real difficulty to continue. Word searches in all kinds of contexts demonstrate the same occurrence on a more temporary basis. In the following, we analyze when and how participants employ the syntactic suspensions as a display of temporary incapacity to maintain simultaneous speech and body movement. This paper will thus contribute to our understanding of how the body and syntax are co-organized, as well as to how bodily strain can be displayed in everyday interaction.

\section{METHOD}

Since the topic of this study concerns bodies under strain, we looked for contexts where participants would be involved in a physical activity. The video data at our disposal included rock climbing $(25 \mathrm{~h})$, and opera rehearsals $(20 \mathrm{~h})$. Both corpora were collected during a period of ethnographic fieldwork (participant-observation at gyms and on outdoor excursions for the climbing, and observing the rehearsals and discussing with participants for the opera). All participants gave informed consent to be recorded and participate in the research. The languages involved are English, Italian, and Swedish. While these activities involve variable accountabilities, e.g., regarding whether strain displays are legitimate or warranted, they extensively mobilize the body. Furthermore, in both activities, the suspension and abandonment of an initiated clause is accountable. In the opera rehearsals, this is much like everyday focused conversation, where some reason must be apparent in order to account for silence. In climbing, though an activity can be achieved silently, if a climber abandons an initiated verbal turn, co-participants will worry the climber is facing a physical problem and would typically make the climber accountable for safety reasons.

In these materials, we looked for signs of syntactic progressivity being affected by the participant's bodily engagement, targeting moments of disruption within an ongoing clause or phrase. The final collection of instances focused on moments when syntax was resumed to some degree after suspension (39 cases: 36 in climbing, 3 in opera rehearsals). Specifically, a syntactic suspension comprises an initiated clause which is then temporarily halted. At the point of halting, where silence occurs, participants treat the clause as accountably incomplete. The clause is then resumed and continued, at least briefly, without (typically, see below) reframing or reinitiating the clause (as is sometimes done in repair). The collection was restricted to cases within a clausal unit, so no other kinds of TCUs were included.
The extracts in this paper include instances where the syntax was brought to completion of a clause (Extracts 2-4, 6, 7, 10-12), as well as deviant cases with 1) ambiguous completion of the clause, but definite completion of a turnconstruction unit (Extracts 1, 8), and 2) eventual abandonment of a clause after initial resumption (Extracts $5,9)$. The unifying feature, then, is the temporary suspension of verbal clause production, with some resumption that continues the initiated clause. While silence characterizes most suspensions (Extracts 1-5, 7-9, 12), we include deviant cases where co-participants speak during the suspension, and where the suspending speaker must then work to re-establish the silence as a suspension (rather than a recruitment of assistance, e.g. through a word search) (Extracts 6, 10, 11). Grunts and heavy breathing were sometimes combined with silence in the suspension (Extracts 1, 8, 9).

Strain was also indexed in the corpora via voice quality (see also Trouvain and Truong, 2015), often near suspensions, although it occurred elsewhere as well. As a frequent cooccurring practice in our activities, "strained voice" (marked $\Sigma$ in the transcripts) will be used as an umbrella term to refer to instances when embodied strain becomes hearable in speech. This includes standard voice qualities of perceptual voice analysis (according to Stockholm Voice Evaluation Approach: Hammarberg, 2000), such as "breathy", "tense", "creaky", or a combination of them.

The method used is multimodal interaction analysis (C. Goodwin, 2000, 2018; Mondada, 2014). This involves a moment-by-moment qualitative scrutiny of every case from an emic (member's) perspective to carve out the characteristics and affordances of the practice. The aim of the analysis presented below is to document the multimodal organization of syntactic suspension in order to reveal its systematic deployment, as well as illustrate its use across two activities and three languages. We do not present frequencies of tokens as may be related to features, speakers, or activities (see Schegloff, 1993 on why quantification would be highly problematic for targeting these kinds of phenomena). We aim to reveal the way in which using the practice is oriented to by the speakers themselves, and both how it is accountable (that is, something that must be made sense of by co-participants, Garfinkel, 1967), and accounts for strain (that is, makes the speaker perceivable as straining). A valid analysis must show not only that the speakers perform the practice in a systematic way, but that it is accountable to do so, i.e., that it is recognizable, and deviation from that systematicity will be questioned by participants, achieve different action, and otherwise fail to be sensible as the same display (see Robinson, 2016). Accordingly, a variety of extracts from the different settings in our corpus are presented to show the prototypical, as well as deviant cases.

\section{ANALYSIS}

Syntactic suspensions have consistent form and pragmatic use, which we will demonstrate through the analysis of a series of 
example cases (Temporally Suspended Syntax as a Social Practice). After that, we will show how silence and breath feature at the point of suspension (What's in a suspension?), specifically how the suspended moment can also include strain cries and moments for breathing. Next, we will show that speakers orient to syntactic suspensions as a recognizable, coherent practice, such that they manage emergent intrusions (Interactional Treatment of the Practice as Coherent). Finally, we show that participants can use the suspensions as conventionalized depictions of strain outside of actual strain events (Conventionalized Use of Syntactic Suspension).

\section{Temporally Suspended Syntax as a Social Practice}

In this first section, we describe the features of suspended syntax. The practice is characterized by a suspension occurring in the middle of an emergent syntactic clause (occasionally in the middle of a word), which is subsequently resumed. The suspension takes the form of a silence, although strain sounds or outbreaths can cooccur with the silence (see the uvular trill in Extract 1, further analysis in What's in a suspension?). The suspension is timed with a moment wherein the body is affected by strain, often the peak of a strenuous movement, but sometimes the out-of-breath "aftereffects" of strain. The continued clause starts where it was suspended, without reframing (as often done in repair, see Extract 6, Extracts 10, 11 for deviant cases).

The following (Extracts 2-5) each show a rock climber suspending their talk at a moment where they perform a strenuous motion. They are of course using their bodies throughout the encounters, and they are each already climbing by the time the extracts begin, but the suspensions occur at some difficult motion. The suspensions occur in the middle of a word (Extract 2, line 5, see Figure 2), a verb phrase (Extract 3, line 2, Extract 4, line 3) and an adverbial phrase (Extract 5, line 5). At each of these points, the TCU is grammatically incomplete, and transition to another speaker is not yet relevant.

\section{Extract 2 | KY 190801 Great Wall gp12_9:16 (See Figure 2).}
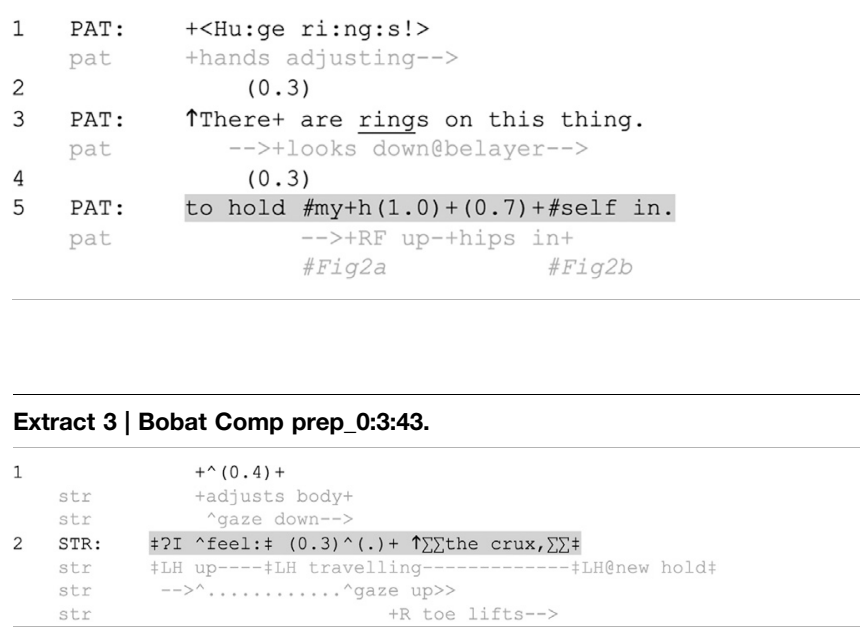

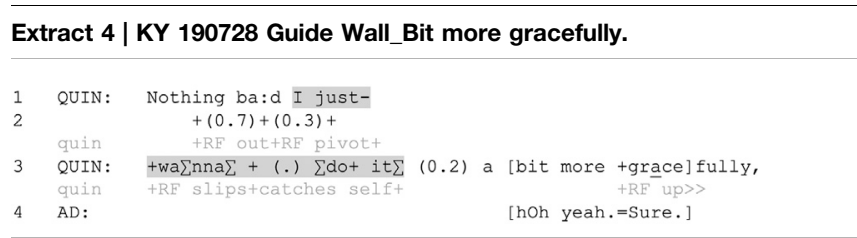

Extract 5 | KY 190801 Great Wall gp12_7:29.

\begin{tabular}{|c|c|c|}
\hline 1 & $\begin{array}{l}\text { PAT : } \\
\text { pat }\end{array}$ & $\begin{array}{l}\mathrm{mhh}+\mathrm{h} \\
\quad+\mathrm{LF} \text { adjust--> }\end{array}$ \\
\hline 2 & $\begin{array}{l}\text { QUIN : } \\
\text { pat }\end{array}$ & $\begin{array}{c}\text { Is there a good hold up there?+ } \\
-->+\mathrm{RF} \text { up--> }\end{array}$ \\
\hline 3 & $\begin{array}{l}\text { PAT : } \\
\text { pat }\end{array}$ & 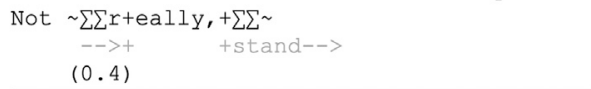 \\
\hline 5 & $\begin{array}{l}\text { PAT : } \\
\text { pat } \\
\text { pat }\end{array}$ & $\begin{array}{c}\sum \text { No } \neq \text { tihllh } \text { t }^{+}(0.3) \neq \text { we start to get to: } \\
\neq \text { RH up-- } \\
-->+ \text { looking around }>>\end{array}$ \\
\hline 6 & & $(2.1)$ \\
\hline 7 & $\begin{array}{l}\text { PAT : } \\
\text { pat }\end{array}$ & $\sum_{->\neq}$Aw $\neq$there it is. $\sum$ \\
\hline
\end{tabular}

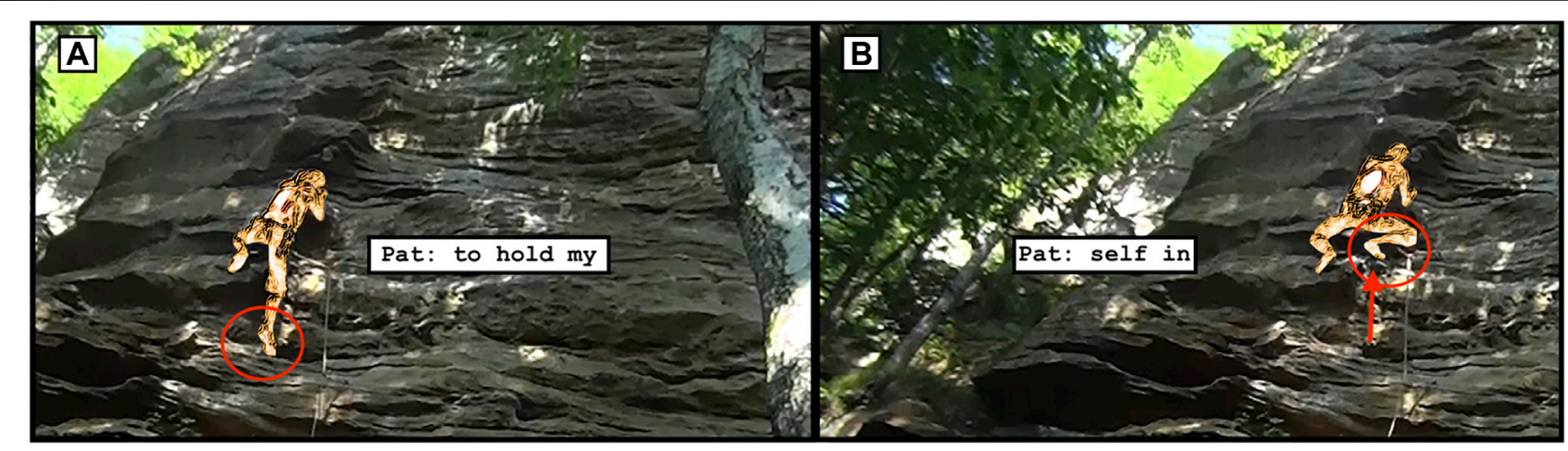

FIGURE 2 | As Pat lifts his foot, he suspends the ongoing word (or noun phrase), completing it (definitively making it a word) once his foot is secure. The figure shows the difference in position from the opening moment of suspension (A) to the moment of resumption (B). If the reader attempts this movement (put one leg half bent on a chair, try to stand up without kicking off, and have someone around to prevent falls), they will find they tense many torso muscles as they lift their second leg and foot into the crouch and may hold their breath, especially if they are unstable. 
As the climbers engage their bodies in additional exertion (especially the abdomen, including the diaphragm, which is associated with the function of breath holding, Parkes, 2006), they suspend their talk. The exertions above include lifting a foot/ leg (Extract 2, line 5; Extract 4 line 2-3), raising a hand while lifting the body (Extract 3, line 2; Extract 5, line 3-5), and catching oneself during an unexpected slip (Extract 4, line 3). The suspensions occur in the middle of a projectable clause, at moments of "maximum grammatical control" (Schegloff, 1996, p.93). For example, beginning with Extract 2, when Pat suspends his speech at "to hold myh" (Extract 2 line 5), he has projected either a noun phrase (e.g. my body) or a compound word (what he ends up producing, myself). This is not a point of possible completion for a TCU (it is, currently, a "fragment," Selting, 2001), and so not a place for the co-participants to take a turn. Pat completes the clause starting the moment his foot gets in position underneath him, which coincides with the moment his muscles can relax, relatively speaking, since he is more securely supporting his weight.

In contrast, when any suspension occurs after a point of possible completion, a co-participant does take a turn. For example, in Extract 4, after two suspensions from Quin that occur in the middle of clauses, the third silence (line 3, 0.2) occurs at a possible completion point of the clause: I just wanna do it. Adam treats this as a potential transition relevance place, and takes a turn (line 4), overlapping Quin's increment (line 3). Thus, even though Quin has just slipped, is currently in the process of stabilizing his body, and may be temporarily unable to continue speech (all of which Adam can see), Adam still treats this particular silence (but not the previous ones) as a transition relevance place. This suggests that the position of the suspension in the middle of a clause, at a position that is not a possible completion point (Schegloff, 1996), is critical to the achievement of the suspension practice. In suspending at moments where the syntax is incomplete, the speaker takes advantage of the normal projectability of syntactic completion. When a clause is incomplete, all of the co-present climbers in the above examples treat the turn "space" as unavailable, as in the middle of the climber's TCU and not an opportunity to take a turn. They do this by withholding talk until a possible completion point. Participants can hold the strain display over significant temporal delays (e.g., 1.7 s, Extract 2 line 5), without co-participants treating the silence as abandonment or a lapse (Hoey, 2020), due to the availability of the bodily preoccupation as an account.

Bodily control is often, though not always, regained at the moment when the syntax is resumed, such as in Extract 5 (line 5): Pat is here trying to balance and find the next hand hold. He displays strained voice while standing up and holding on with only one hand, but once he gets his legs fully extended and stops reaching with his hand, he has better balance and weight distribution. At this point, the strained voice also stops, and the clause is resumed. In Extract 3, where the strained voice is instead added after the syntax is resumed (line 2), the climber has not yet quite reached a moment of rest, although he can anticipate reaching it when he gazes up shortly before resuming the clause (line 2). The climber's utterance describes the hardest part of the climb as it is happening, so the remainder of the clause is squeezed out in a strained voice. Continuing the clause, through ongoing strain, displays a barely maintained ability to utter speech. These complementary examples show how suspending syntax permits the straining body to display that it has reached a moment when speech is temporarily unsustainable with bodily activity, but also creates an opportunity, by holding the turn, to demonstrate the prospective resumption of control.

That this is a display, not just a physiological byproduct, is evident in that the speakers are capable of timing their speech to occur in moments of strain. For example, in Extract 2, Pat produces a complete clause without a suspension (line 3 ). This co-occurs with hanging, rather than moving; Pat is relatively relaxed and unstrained in this position. Climbers are not forced to move at any given point, nor are they required to talk while climbing (as above) or demonstrating a motion (as with opera rehearsals, below). Yet Pat continues to speak (line 5) when initiating and undergoing a movement that causes bodily strain. By designing or permitting talk to co-occur with motion and strain, the participants create the conditions wherein a syntactic suspension can function. In other words, timing talk to co-occur with motion and strain provides a slot in which a display of that strain can be done with suspended talk, as the body provides a visible account for suspending syntax. Speech can be prioritized even over physiological needs, such as full ventilation (Hixon et al., 2018), and the syntactic suspensions take advantage of the ability to switch between priorities, live. The body's motion is concurrent with the entire utterance, however in the silent moment, the body is rendered as the most salient part of the display-by removing language production, the body becomes the main focus of attention. The suspensions are timed to strategic moments that highlight relevant issues for the speakers, such as a challenging body position or move.

Suspensions do not only occur in canonically bodily intensive activities like exercise. In Extract 6, at an opera rehearsal, the body is likewise made salient at the moment when a minor strain becomes too great. This is an example of Swedish opera performers and their director trying out initial ideas on how to embody a scene. Since the baritone (BAR) will be mourning over the soprano as she dies, the director (DIR) has suggested they try it with the baritone seated on the floor, and the soprano (SOP) lying in his lap. This creates a difficult position for singing. In opera performance, effort should, of course, not be revealed in the voice, so it is relevant for participants to note and remove strain in rehearsal. In lines 1-2, the baritone launches talk about a scene and characterizes it in a copula clause de e såhär handfast "it's hands-on like this". He then begins to experiment on line 4, launching a proposal of how he might move här måste han liksom bara "here he just has to," before trying to lift the soprano into his arms. The lift (lines 5-11) takes several efforts to accomplish (see Figure 3), across which the baritone suspends syntax. 


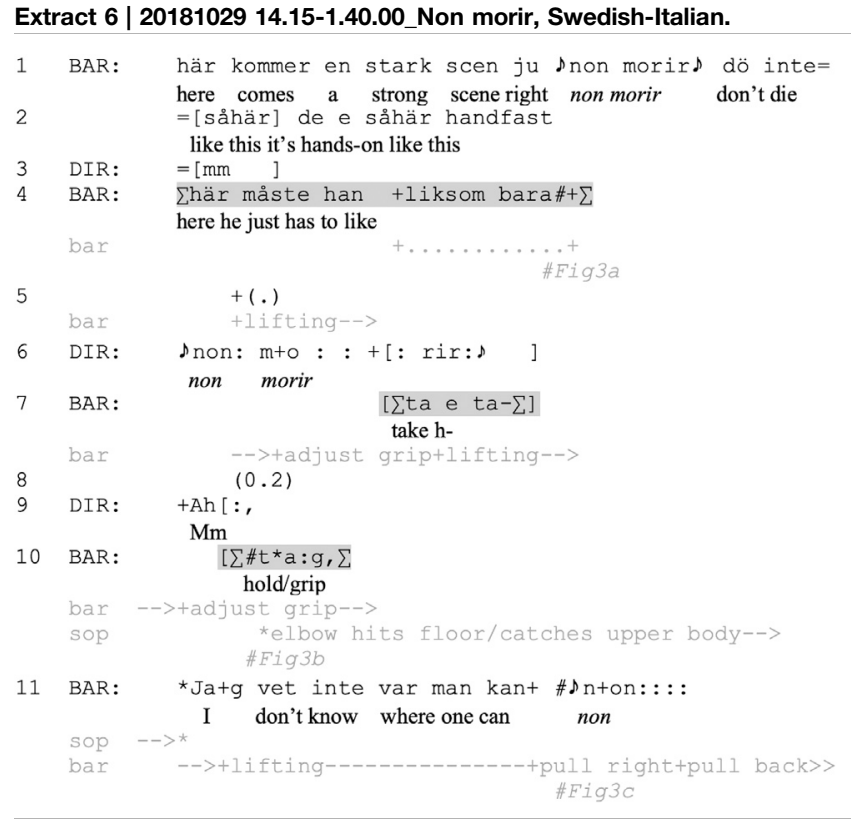

The first suspension occurs after the adverbial bara "just" when the baritone is lifting the soprano. In the silence, the director co-animates the baritone's proposal by voicing the musical lines that he should perform at this point (line 5). However, as an instance of our focus phenomenon, in line 7 , the baritone produces a continuation and completion of his launched syntactic structure: här måste han liksom bara ta e $t$ - tag "here he just has to take hold/grip" (lines 4-10). This emergent completion retroactively characterizes the incomplete syntax and his silence (line 5 and line 8) as part of a suspension borne of strain, rather than the opening of an embodied depiction (which "bara" can project, Eriksson, 1995). The abandonment of $t a$ - (line 7) coincides with a slightly higher lift by the baritone, and together with the following pause (line 8), this achieves yet another display of strain, albeit in the form of repair (particulars of how our phenomenon unfolds with repair will be discussed in Interactional treatment of the practice as coherent below.)

The baritone does further work to achieve the suspension as strainmotivated. His prosody from här måste onwards is marked by strained voice, as with the climbing examples, demonstrating the tightness of his muscles. The baritone produces this strained voice even when anticipating, and not yet doing, the lift of the soprano (line 4). Later, when stating his uncertainty about how to do the action (line
11), there is no strained voice, even though he is still lifting the soprano up. The strain is focused at the moment of initiating the action, helping to project for the soprano that the lift is beginning, and for both Soprano and the director that the lift is effortful_-something that may be highly problematic in the product of operatic singing later.

We can thus see across activities that suspended syntax renders salient the current strain in the speaker's body, as a social action. The practice displays a balance between ostensibly being overwhelmed by bodily strain (temporarily suspending talk) and control (being able to continue talking). The periods of silence coincide with a successful achievement of a strenuous move. Syntax is interrupted at moments of "maximum grammatical control," where the TCU is accountably incomplete through the launched-but-incomplete-clause, which helps hold the turn for the current speaker so they may resume the syntax after the silence. In the next section, we compare the different practices used to display strain at moments where syntax is interrupted.

\section{What's in a Suspension?}

Once syntax is suspended, speakers have several options for the unfolding turn, including producing silence, hearable outbreaths, or grunts. Silence is coordinated with strain peaks and bodily motion (see Interactional treatment of the practice as coherent below for deviant cases). Extract 7 below demonstrates the silence format, with the spectrogram (see Figure 4) showing the lack of sound emerging in the suspension. In this example, Quin suspends syntax in the midst of complaining about the beginning of the climb. The suspension emerges just before he reaches ("LH over") for another hold.

\section{Extract 7 | 190729 KY Bruise Bros_16.10_Start.

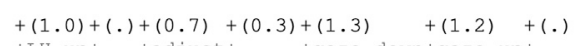

As Quin selects and moves to a better position, he temporarily takes up more weight in his other muscles, causing additional strain. This occurs just as he resumes syntax, resulting in the word "not" being produced with strong emphasis and a rise in pitch. These prosodic changes have a plausible physiological connection: the extra pressure in the vocal tract may arise from muscular adjustments involved in increasing stability in the torso (Hodges et al., 2005; Massery et al,, 2013). The enaction of this muscular effort creates that bodily event of stability, because the muscles must assume the stability-providing shape

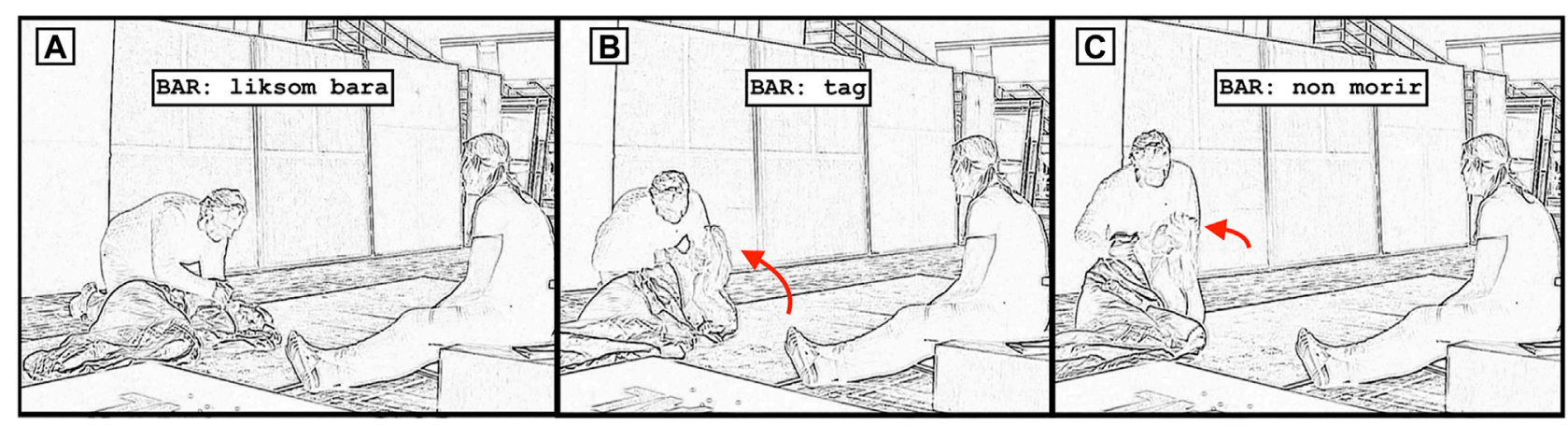

FIGURE 3 | The baritone suspends syntax as he undertakes to lift the soprano. 

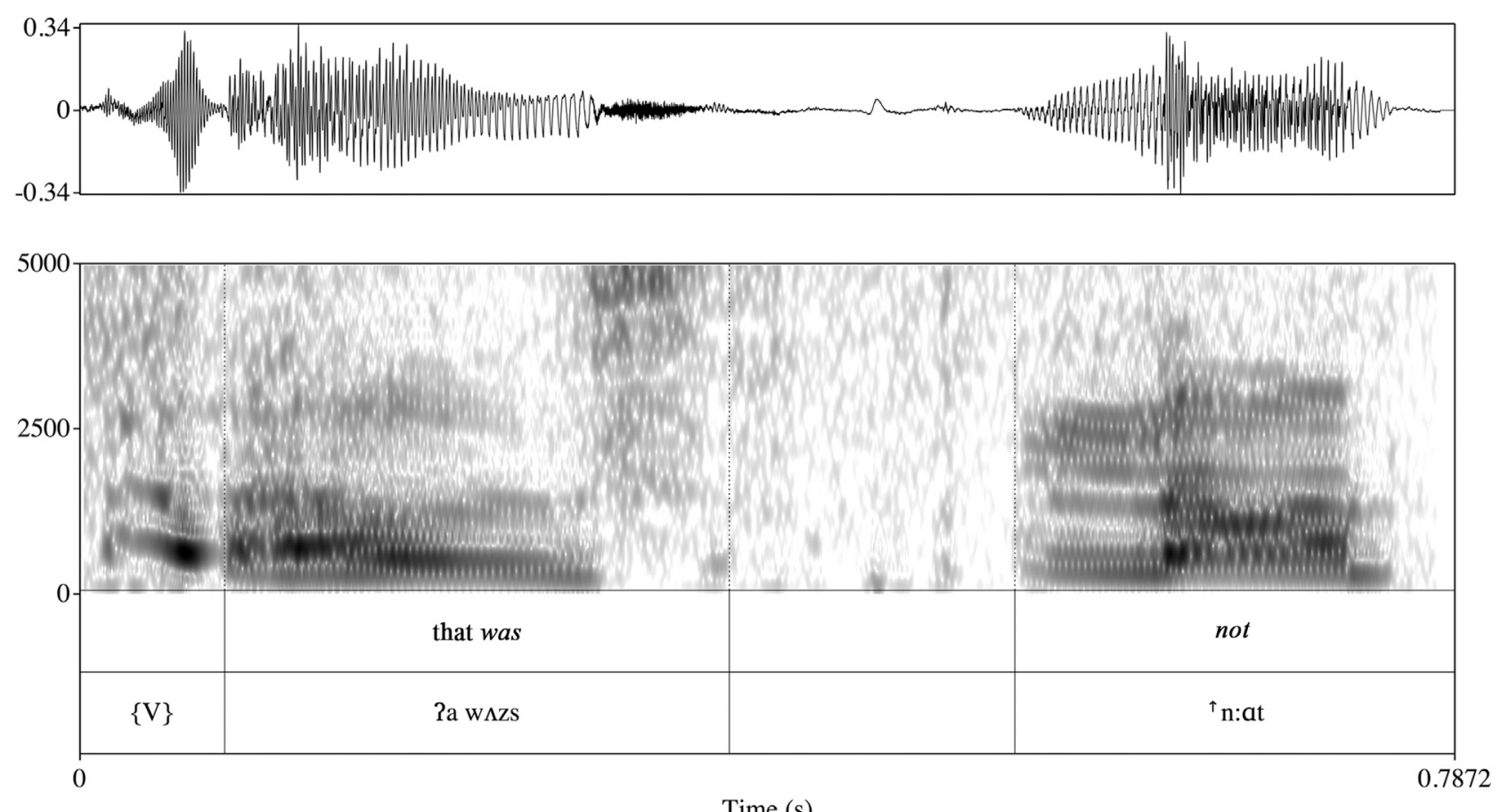

Time (s)

FIGURE 4 | A spectrogram of the suspension in Extract 7 between the words was and not. Note that any sound in the spectrogram between was and not is due to environmental noise, as they are outside. This suspension is characterized by silence. $\{\mathrm{V}\}$ is an indeterminate squeaky vowel sound.

in order to produce the prosody, even if the stability itself is not strictly required. In other words, whether the display arises from airflow requirements, or airflow is suspended in order to do the display, the physiology and social action are inextricably bound together.

Another way to enact ongoing bodily effort is to preface or intersperse the suspension with breathiness or outbreaths, as if "catching one's breath" (a feature also found in experimental instances: Trouvain and Truong, 2015), likely reflecting the body's increased need of oxygen due to the strenuous activity (Hixon et al., 2018). In Extract 8, the Swedishspeaking climber (CLI) has just completed a climb and is looking down from the top of the boulder. He is breathing heavily (line 2, 6), and when he appears to have enough breath to talk again, he begins to assess his climbing performance with a beginning of a routinized assessment format vad "how". However, before continuing the syntax, he takes another breathing break (middle of line 8), and still does not make it to a grammatical completion. The next word is creatively assembled, rather than a conventional continuation (oform "nonshaped/out of shape") but as an evaluative item it pragmatically continues the projection from the format-initial item.

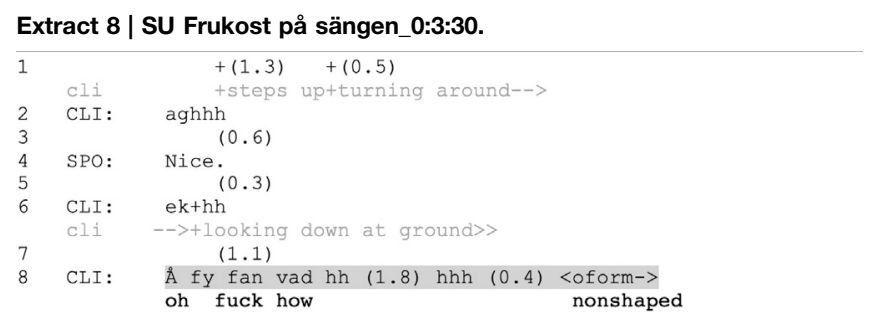

The outbreath in line 8 manages the body in a different way from silence: instead of appealing to the embodiment of breath holding (and its relevancy for torso stability in a difficult motion), the heavy breathing displays that the speaker enacts having experienced strain and currently not having enough air to complete the projected phrase. As shown above, this may be a way to accomplish a display of strain, via suspension of syntax, after the strain event has concluded (see also Extract 2). The climber is not actively undergoing the difficult motion at the time of speaking; he has just completed the climb. Heavy breathing may be physiologically necessary after strain, but it can also be deployed at specific moments to accomplish a syntactic suspension; the climber chooses to describe his climb now, rather than wait for his breathing to ostensibly be normal. In this way, both glottal closures and heavy breathing can occur during the intra-TCU silence, and tie the display to slightly different bodily demands. In a similar manner, Pehkonen (2020) has argued that by using the semi-conventionalized Finnish token huh huh participants externalize their physiological state of "being out of breath" and take a stance towards the triggering event. Suspended syntax seems to be another practice of stance-taking; the strain displayed by the halt in speech production orients to the prior event(s) as strenuous, and as having various qualities (tough, involving excess strain, etc.).

There is yet a third option in formatting suspensions that are associated with strain: producing a strain grunt. Grunts were briefly described by Goffman (1978, p. 803), as sounds that serve to warn others that "nothing else can claim our concern," similar to how we have described the way syntactic suspensions bring the body to prominence. Grunting in our data consisted of a short burst of guttural vocalizing, usually with a glottal onset and low open or mid 
vowel. Most grunts in the climbing data corpus (365 out of the 368 found) did not interrupt syntax, either occurring as stand-alone utterances, or preceding or ending an utterance that had a complete clause. The few grunts that interrupted syntax resulted in the abandonment of the clause, rather than its temporary suspension, as the following extract shows. Below, Pat is trying to find a safety bolt in a strenuous position. At first, he uses syntactic suspension (line 2), but after a long pause and a grunt, the clause remains unfinished and instead he launches another clause.

\section{Extract 9 | 190801 KY Great Wall reg5_2.33_10a.

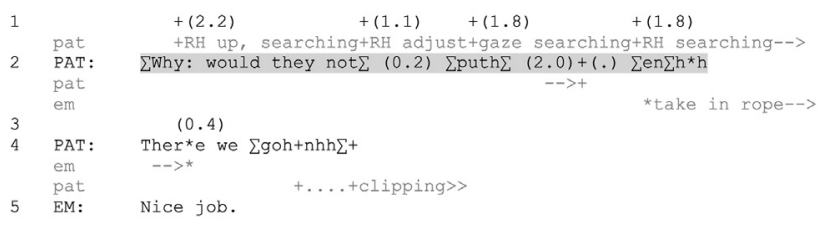

The clause that Pat started suddenly becomes irrelevant, as he discovers the safety bolt just before the silence ends. The grunt (line 2, "enh") occurs as Pat repositions his hand to have proper leverage to connect his rope to the safety bolt. In other words, once it becomes pragmatically unnecessary to complete the clause, the suspension is interrupted, in this case by a grunt. The grunt reorients to the physical effort involved in grasping the hold and using the bolt, and may act as an upgrade of further strain that occurs while a suspension is already ongoing. This suggests that grunts may allow exit from a suspension that can no longer be achieved coherently.

In contrast, similar strain sounds may provide reentry into the completion of a suspended phrase. Reconsider Extract 1 (line 3, transcribed as "R"), the word much is prefaced by a uvular sound, and the initial $\mathrm{m}$ is lengthened and infused with strain, thus delaying syntactic progressivity. The seeping of air through the strained vocal tract may indeed index inability to continue but, in Extract $\mathbf{1}$ at least, the syntactic structure nevertheless emerges as complete. In fact, the strain sound may preempt co-participation by getting vocalization on record, and then merges the sound into the opening of the syntactic resumption. A grunt produced as a standalone token, as Extract 9 above shows, may provide the opposite affordance. As in all other instances of suspended syntax, this carefully balances displaying physical preoccupation and sufficient control of the vocal apparatus to intermittently produce speech.

Silence, outbreath and strain sounds are thus treated as different components of the syntactic suspension practice. While grunts and breathiness can also achieve strain on their own, syntactic suspensions uniquely allow the speaker to display re-established bodily control, through the (smooth) resumption of syntax.

\section{Interactional Treatment of the Practice as Coherent}

We argue that syntactic suspensions are not merely by-products of bodily demands, even if they are interwoven with such demands. As evidence that they are a member's practice (Garfinkel, 1967; Sacks, 1992)-that is, recognizable and reproduceable for pragmatic action-we now demonstrate below that speakers orient to, and work to maintain, the coherency of the suspension as a practice. Syntactic suspensions are not just any emergently formed clause with a discontinuation. The suspension occurs at specific moments and alongside systematic practices for excluding co-participation in the clause. This section will analyze how the strained participants actively restrict co-participation in the clause, to allow for achievement of the clause as if temporarily suspended due to strain.

Let us first return to Extract 6 (reproduced below as Extract 10), wherein the baritone was demonstrating how he might lift the soprano into his arms. In this extract, we can see the inherent risk in using suspended syntax as an effort display; especially in some syntactic constructions it is vulnerable to being treated as a syntactic preface to a bodily completion (line 4) (Keevallik, 2018). The syntactic structure that has been begun is här måste han liksom bara "it's hands-on like this and here he just has to like and comes to a halt after bara "just". This could introduce a bodily completion (the lift, line 5 onwards), and the director appears to treat it as such by providing the relevant sung line that would accompany that movement. However, the baritone subsequently extends the clause (line 7), eventually resolving the syntax as an instance of suspension arising from strain.

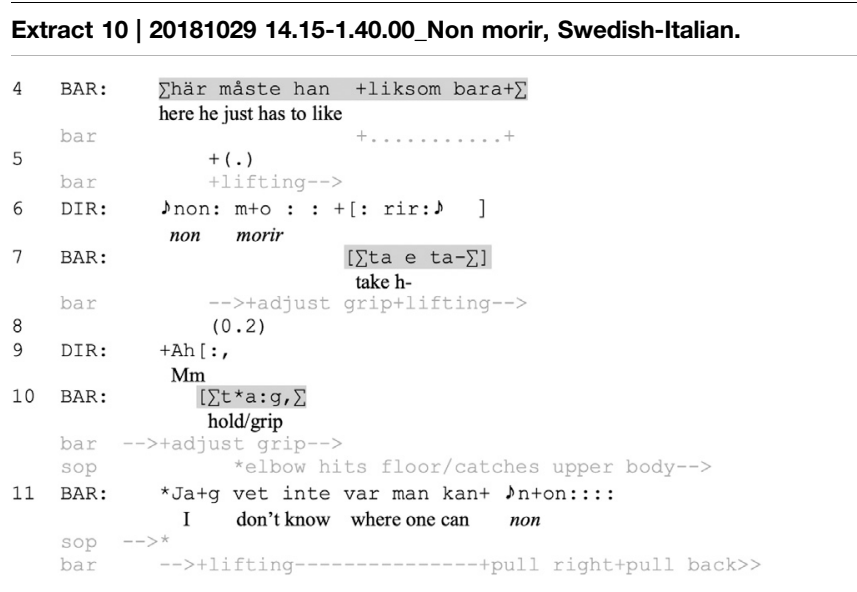

During the opera rehearsal, bara or its shortened form $b a$ (Eriksson, 1995) is frequently used to introduce depictions-embodied iconic representations of distal "scenes" (Clark, 2016), also known as for instance animations (Cantarutti, 2020), reenactments (Sidnell, 2006b) and reported speech (Holt, 2007). It is therefore possible to treat the syntax as completed by the bodily movements of the baritone (see Keevallik, 2018); his embodied depiction can act as an alternative to the complement of the projected clause. The director treats the ensuing actions in this way, by positioning herself as a co-animator of the embodied depiction and voicing the musical lines that he should perform at this point (line 6). Furthermore, the strain involved in the lift is visually available, as the baritone has not yet finished successfully lifting the soprano and appears to be repeatedly readjusting his grip. Co-animating at this point supports the baritone's depiction by providing libretto material he may not be able to produce. However, the baritone does not orient to the director's co-depiction, overlapping it with an utterance voiced as himself, the performer, rather than as his character: he describes his attempts to get a grip on the soprano in order to lift her (line 7-10), in synchrony with his physical attempts to do so. The director, in response, likewise switches from a depiction of the baritone's 
character to commentary as herself, a director, in the current action (line 9, a continuer). The baritone thus bypasses the director's contribution in the depiction, reorienting them both to the ongoing physical strain in his performing body. In retrospect, this emerges as a syntactic suspension of the structure liksom bara ta tag "has to like take hold" whereby the director's singing ends up being treated as a side activity.

Suspensions are in general vulnerable to co-participation, since, if the pause is long enough, they can encourage coparticipants to treat the ongoing clause as either abandoned or in need of assistance to be completed (M. H. Goodwin and Goodwin, 1986). For example, the director, above, supplies the baritone's sung lines in the absence of the baritone providing them himself. However, in the following example from rock climbing, when such assistance is offered, the original speaker rejects the contribution, and reattempts the suspension in the clear of co-participation. Below, Pat has just abandoned doing a "roof" climb that was too hard for him that day. As his feet touch the ground, he appears to assess his shaking arms (Lookh at thath, line 1) as notable, before suggesting an alternate next climb. His speech is marked by breathy phonation (see also Extract 8).

\section{Extract 11 | 190113 RL4_Let's do some nines.}

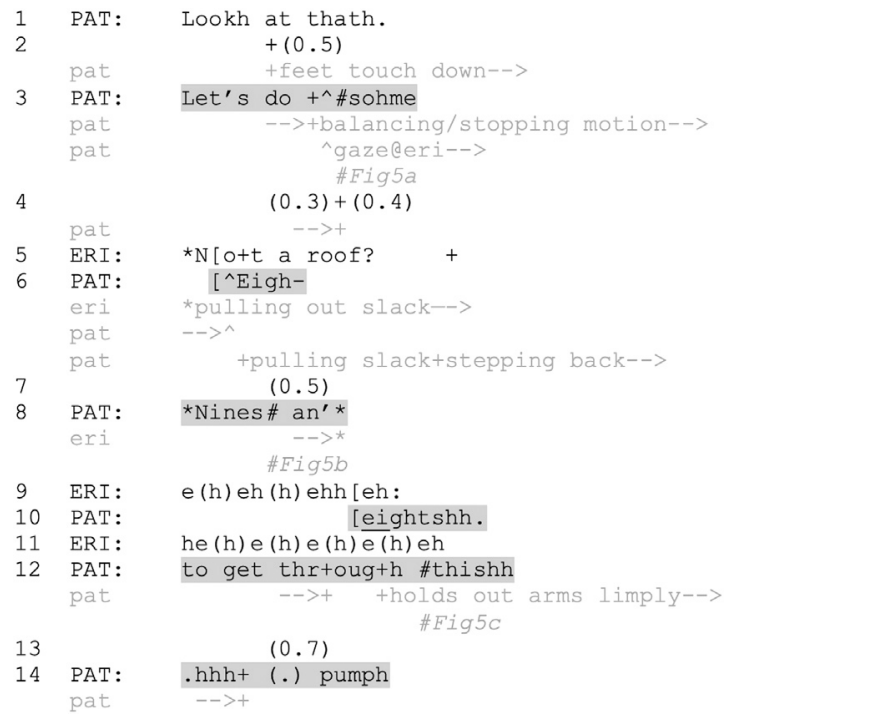

When Pat suspends his syntax after Let's do sohme (line 3), Eric at first withholds co-participation, possibly until Pat regains his balance (line 4). However, after a lengthy silence (line 4), during which Pat gazes at Eric (lines 3-6, see Figure 5A), Eric supplies a possible option, not a roof, which pragmatically, although not grammatically, completes the TCU (line 5). This co-participation ends up being in overlap with Pat's next installment of the ongoing clause (an "eight" or "nine" being a type of climb, specifically a degree of difficulty, much as a "roof" is a type of climb, though not an official difficulty grade) (line 6). Instead of agreeing with Eric's suggestion (e.g., by uttering "yeah," or "exactly"), Pat restarts his syntactic completion (lines 8-10), including an insertion (S. Wilkinson and Weatherall, 2011) of nines. Insertions between the first and second half of the suspended clause are unusual for the

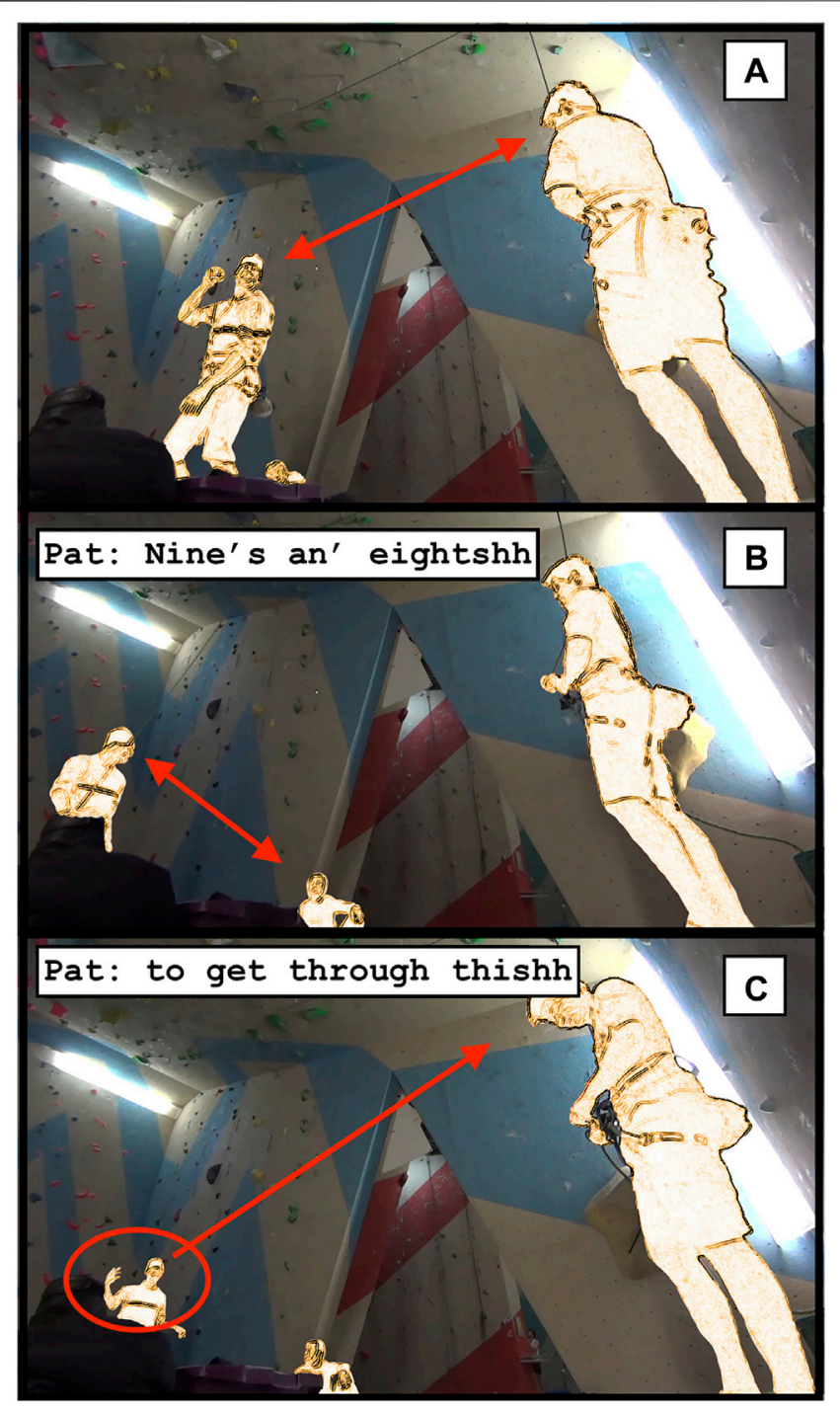

FIGURE 5 | Pat (on the left) gazes at Eric (on the right) while getting his balance, potentially recruiting Eric to help him complete the phrase he started (line 3). Instead, Pat (re)completes the phrase himself (lines 8-10).

collection, but co-participation is also rare. Pat also withdraws his gaze from Eric here (see Figure 6B), reducing the relevance of a collaborative completion. Furthermore, Pat not only re-starts his attempt to complete the prior suspension, but also initiates a second suspension (between lines 12-14, see Figure 5C). In this way, Pat gets a syntactic suspension on the record that is neither influenced by a co-participant, nor modified by any sign of self-repair. Pat also adds extra practices for displaying strain that were less present in the first attempt: there is more breathiness (lines 10, 12,14 ), and also a visual display of his tired body (line 12). In this case, the suspension does not coincide with a strenuous move itself but rather with a display of physical exhaustion from prior strain that ostensibly prevents the speaker from producing continuous syntax (see also Extract 8). Thus, in contrast to suspensions during strain that featured breath holds and strained voice, this one involves heavy breathing. At the same time this 
instance again evidences the careful balance between being too exhausted to do a roof but still sufficiently capable of uttering snippets of syntax. Exhaustion is here designated by the breathy voice and intermittent panting and speaking.

Both Extracts 10, 11 exhibit self-repair work, ta e- ta- ta:g "take hold/grab" and eights- nines and eights respectively. Most instances of our suspension collection do not involve any insertion or reformulation after suspension, but instead directly resume the clause where it was suspended. Notably, both of these extracts with self-repair modifications occur in moments with overlap. In Extract 10, the director first receipts the baritone's utterance as prefacing a demonstration syntactically, and so takes it that the turn space is open vocally. In Extract 11, Pat meets Eric's gaze (lines 3-6) during the silence, which can be a strategy for inviting a co-participant into a word search (M. H. Goodwin and Goodwin, 1986). Eric takes this invitation and supplies a potential completion. In both cases, redoing a suspension gets it on record $a$ s a suspension, rather than as some other action with co-participation (e.g., demonstration, word search or other inability to complete sentence).

The coherency of the syntactic suspension as a social action rests on being able to maintain silence without intervention and resuming the syntax oneself, and participants work to ensure this coherency occurs. We have thus seen that speakers work for the syntactic suspension to emerge as a coherent and public pattern: when the display of strain or its after-effects is at issue, interlocutors contributions to the ongoing syntax would disrupt the socially relevant display.

\section{Conventionalized Use of Syntactic Suspension}

The above analysis demonstrated how suspended syntax is accomplished and how participants manage potential incursions on the practice. In addition, syntactic suspensions can be used as a depiction (Löfgren and Hofstetter, 2021), in this case a depiction of strain where participants are not actually engaging in effortful activity but demonstrating what such activity looks like. Suspended syntax appears to be a conventionalized enough practice to be used as such a depiction of effort.

For example, in Extract 12 below, the director at the opera rehearsals depicts strain by suspending syntax in the middle of a quoted line from the libretto. The suspension is done as part of a depiction of the baritone's character slowly moving into a kneeling position (line 7, see Figure 6).

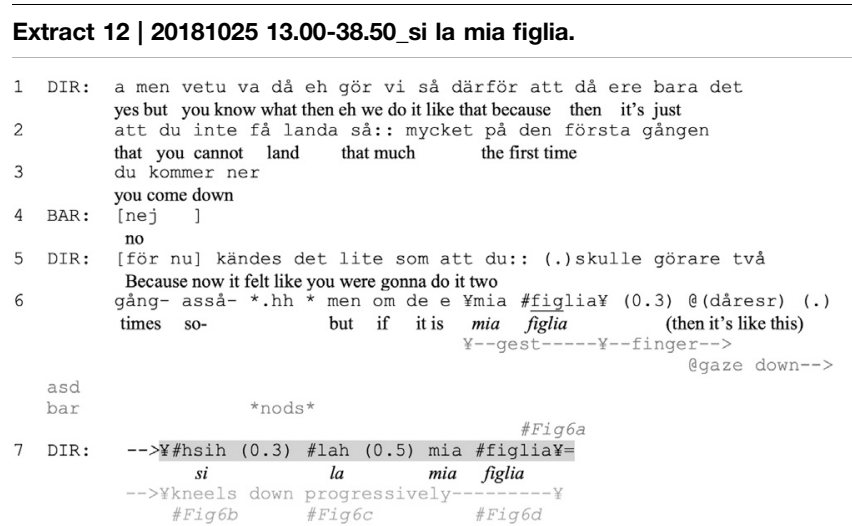

At line 7, the director begins depicting someone bending down with difficulty, singing si la mia figlia "yes my daughter" in Italian, while embodying the character of the baritone. Between si "yes" and la (article), as well as between $l a$ and mia figlia "my daughter", there are suspensions of the line's progression (line 7), while at each suspension she moves her body a bit further towards the floor (see Figure 6). In addition, the director's talk is produced throughout with a breathy voice quality. Together, these features serve as a depiction of how, for the character of the baritone, who is physically hindered, the descent towards the ground is causing effort (see Syntactic disruptions as a sign of bodily concerns on bodily concerns and syntactic suspension). The director herself is able to get down to the floor without difficulty, as seen in other moments in the data. The strain is thus imaginary but made available as something the baritone can reproduce when performing in character.

Temporal syntactic suspensions can thus be used to depict strain even in the absence of local physical effort. The suspension accomplishes the display, representing the out of breath or strained state of the body. Syntactic suspensions, as the multimodal practice described in this study, are thus usable to depict strain, even conventionalized enough for performances on a stage. This is not to say that all suspensions are conventionalized to depict strain, but that the practice of suspending syntax has one use that is highly recognizable as strain-related.

\section{DISCUSSION}

We have demonstrated that speakers use syntactic suspension to display strain, specifically peaks of strain or the after-effects of strain in interaction. This practice involves temporarily halting and then resuming, an emerging clause and coordinating the suspension with bodily strain. The technique takes advantage of simultaneous physiological and interactional demands on a person and connects those demands into a coherent practice. The exact syntactic structure, however, can vary considerably. Our structures ranged from copula constructions to verb phrases ( $t a$ tag "take hold/grip", Extract 6) and noun phrases (la mia figlia "my daughter", Extract 12) to compound words (myself, Extract 2). It is the general projective capacity of syntax that participants make use of to keep their rights to continue the turn. Even though for the sake of clarity we focused on clauses, as some of the most consistent syntactic structures, we do not imply that similar practices could not be used at other syntactic or turn positions. The aim was to target a central structuring capacity of syntax.

This paper contributes to the larger endeavor of understanding how language is coordinated with, and emergent from, the body, as well as how the body asserts itself and is made relevant by participants in various activity settings. Inhabiting a body simultaneously affords and constrains (or may be taken to constrain) vocal action. Crucially, in contrast to numerous earlier studies that have dealt with pauses and disruptions in terms of mental problems, such as memory lapses or cognitive effort (Clark, 1994; Postma, 2000; Clark and Fox Tree, 2002), we are here proposing a physical 


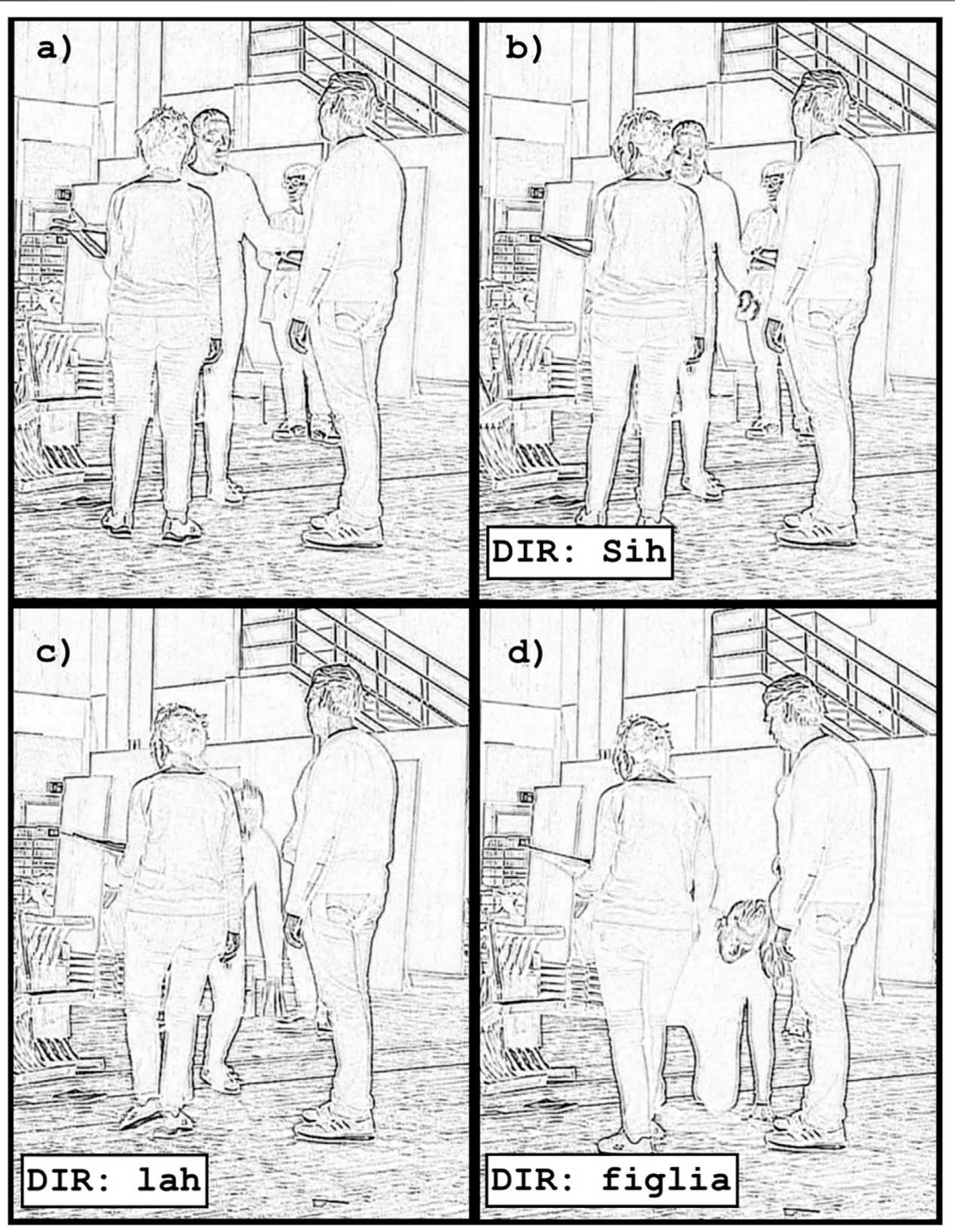

FIGURE 6 | The director progressively kneels down, demonstrating the effort it would take for the baritone's character to do so.

connection to those features in talk. The body and syntax account for each other, with suspensions and bodily strain mutually providing for each other's occurrence. Vice versa, the uninterrupted production of syntax implies no major concern with the body. With syntactic suspensions, the body is or has been visibly engaged in a strenuous motion. The strenuousness of these motions is available to co-participants through their own embodied understandings of the body's demands. This member's understanding of the embodiment of strain is further heightened with specific familiarity with the activity; climbers will better understand the strain inherent in climbing, singers with singing in awkward positions, etc. Furthermore, in more mental activities, such as word searches, the source of the trouble is not typically visibly available to co-participants, compared with the activities presented in this paper. Even in the case of communicative deficits, speakers may need to explicitly alert co-participants of the reason for atypical speech (R. Wilkinson and Morris, 2020), and the solution to any given momentary, situated disfluency is not always easily available. Thus, among other things, the availability of bodily behavior in our practice constitutes a methodological advantage in anchoring the analytic procedures in visible evidence. 
The relationship between the body and language is made starkly apparent by the suspended syntax practice. It is both a display and an embodied event, regardless of the authenticity of the strain. Intense strain may literally, at times, require the suspension of speech, but the speakers also nevertheless seem to be able to design the timing of the suspension as well as its resumption so that it is coherent with syntax. Even if the strain is not literally overwhelming the breath, in order to accomplish a breath hold, the body must inhabit the necessary muscular form to cease producing vocal sounds, and thus perform the embodiment that provides bodily support for strain. Similarly, heavy exhalation requires physical effort. It is therefore artificial to categorically separate display from strain and strain from display.

Since speakers have some degree of choice over when they speak concurrently to moving (in climbing, they can choose when to move; in opera rehearsals, they are actively deciding how to time movement with the opera text), it is justified to consider the affordances of timing speech to co-occur with strain and motion. In our data, the climbers and performers often explain their actions, providing "running commentary" that accounts for difficulties or choices with motion as they appear. We have shown that participants can time their verbal contributions to co-occur with moments of relative ease or rest (see Extract 2). By timing them with the strenuous motion, they both tie the verbal contribution to the body and create the conditions where a syntactic suspension can function as strain. Similarly, we have shown that participants can depict strain through the syntactic suspensions (see Extract 12). Thus, the iconic nature of the suspensions is an available resource to participants and seems to particularly highlight moments of intense strain.

It is a members concern to know when a climber is at peak strain, for reasons of safety as well as communication; similarly, with rehearsals, it is important to know what positions are acceptable for singing and what dramatic actions correspond to the esthetics of the current performance. Each activity has its own contingencies and norms concerning what is a legitimate and warranted display of effort. For instance, in the climbs above, the co-participants do not treat the suspended syntax as a sign of trouble (e.g., danger), nor as a sign of illegitimate strain (e.g., being on too difficult a climb), but as adequate and appropriate displays for the task at hand. In contrast, other activities such as tennis, have (in)famously experienced controversy over grunting and its appropriateness (e.g. Kaskan and Ho, 2016). Further study may elucidate how syntactic suspensions compare to strain grunts, power screams, and other strain signs, or alternative ways of highlighting that one attends to the own body. What is apparent so far is that these other displays only rely on production of a particular vocal token (a grunt) or prosodic quality, whereas suspensions also take advantage of syntax and silence.

The way in which these vocal behaviors are tied to embodied action (through timing, but also quality of sound and movement) may be in part a method for taking advantage of bodily events, but it also has a social history that conventionalizes the co-occurrence of the linguistic features with bodily action into depictive practices. Syntactic suspensions connect the complementary occupations of the body in physical effort and in producing language, and demonstrate a practice through which participants display the intimate connection between language-inclusive of syntax-and the body.

\section{DATA AVAILABILITY STATEMENT}

The original contributions presented in the study are included in the article, further inquiries can be directed to the corresponding author.

\section{ETHICS STATEMENT}

The studies involving human participants were reviewed and approved by the ethics review at Linköping University and Loughborough University. The patients/participants provided their written informed consent to participate in this study.Written informed consent was obtained from the individual(s) for the publication of any potentially identifiable images or data included in this article.

\section{AUTHOR CONTRIBUTIONS}

All authors listed have made a substantial, direct, and intellectual contribution to the work and approved it for publication.

\section{FUNDING}

This project was supported by the Vetenskapsrådet (2016-00827).

\section{ACKNOWLEDGMENTS}

Thank you very kindly to the reviewers, Marina Cantarutti and Rein Ove Sikveland, for their insightful and excellent comments. Thank you to our Frontiers managing editor. Thank you to the editors for the research topic, specifically to Xiaoting Li and Simona Pekarek Doehler for coordination and very helpful commentary. The authors were additionally greatly assisted in the auditory analysis for this paper by Richard Ogden, Uwe-Alexander Küttner, Marina Cantarutti, John Local, and Taylor Jones-thank you very much. Any problems remaining are the authors' own. Thank you to Sally Wiggins and Hannah Pelikan for additional comments and support with the analysis development. 


\section{REFERENCES}

Aaltonen, T., and Laakso, M. (2011). Halting Aphasic Interaction. Creation of Intersubjectivity and Spousal Relationship In Situ. Cam 7 (2), 95-106. doi:10.1558/cam.v7i2.95

Auer, P., Bauer, A., and Hörmeyer, I. (2020). "How Can the 'Autonomous Speaker' Survive in Atypical Interaction? the Case of Anarthria and Aphasia," in Atypical Interaction: The Impact of Communicative Impairments within Everyday Talk. Editors R. Wilkinson, J. P. Rae, and G. Rasmussen (Springer International Publishing), 373-408. doi:10.1007/ 978-3-030-28799-3_13

Auer, P. (2009). On-line Syntax: Thoughts on the Temporality of Spoken Language. Lang. Sci. 31 (1), 1-13. doi:10.1016/j.langsci.2007.10.004

Auer, P., and Pfänder, S. (2011). Constructions: Emerging and Emergent. (Berlin: De Gruyter). https://www.degruyter.com/view/title/37335.

Bloch, S., and Beeke, S. (2008). Co-constructed Talk in the Conversations of People with Dysarthria and Aphasia. Clin. Linguistics Phonetics 22 (12), 974-990. doi:10.1080/02699200802394831

Bögels, S., Kendrick, K. H., and Levinson, S. C. (2020). Conversational Expectations Get Revised as Response Latencies Unfold. Lang. Cogn. Neurosci. 35 (6), 766-779. doi:10.1080/23273798.2019.1590609

Broth, M., and Mondada, L. (2013). Walking Away: The Embodied Achievement of Activity Closings in mobile Interaction. J. Pragmatics 47 (1), 41-58. doi:10.1016/j.pragma.2012.11.016

Cantarutti, M. (2020). The Multimodal and Sequential Design Of Co-Animation As a Practice For Association In English Interaction [Doctoral Thesis]. York: University of York.

Chevalier, F. H. G., and Clift, R. (2008). Unfinished Turns in French Conversation: Projectability, Syntax and Action. J. Pragmatics 40 (10), 1731-1752. doi:10.1016/j.pragma.2007.12.007

Chomsky, N. (1965). Aspects of the Theory of Syntax. MIT Press.

Clark, H., and Fox Tree, J. E. (2002). Using uh and um in spontaneous speaking. Cognition 84 (1), 73-111. doi:10.1016/S0010-0277(02)00017-3

Clark, H. H. (2016). Depicting as a Method of Communication. Psychol. Rev. 123 (3), 324-347. doi:10.1037/rev0000026

Clark, H. H. (1994). Managing Problems in Speaking. Speech Commun. 15, 243-250. doi:10.1016/0167-6393(94)90075-2

Enfield, N. J. (2009). The Anatomy of Meaning: Speech, Gesture, and Composite Utterances. Cambridge University Press. doi:10.1017/cbo9780511576737

Eriksson, M. (1995). A Case of Grammaticalization in Modern Swedish: The Use of Ba in Adolescent Speech. Lang. Sci. 17 (1), 19-48. doi:10.1016/0388-0001(94)00015-A

Evans, V. (2006). Lexical Concepts, Cognitive Models and Meaning-Construction. Cognitive Linguistics 17 (4), 491-534. doi:10.1515/COG.2006.016

Ford, C. E., Thompson, S. A., and Drake, V. (2012). Bodily-Visual Practices and Turn Continuation. Discourse Process. 49 (3-4), 192-212. doi:10.1080/ 0163853X.2012.654761

Fox, B. A., and Robles, J. (2010). It's like Mmm: Enactments with It's like. Discourse Stud. 12 (6), 715-738. doi:10.1177/1461445610381862

Fox, B. A., and Thompson, S. A. (2010). Responses toWh-Questions in English Conversation. Res. Lang. Soc. Interaction 43 (2), 133-156. doi:10.1080/ 08351811003751680

Fox, B. A., Wouk, F., Hayashi, M., Fincke, S., Tao, L., Sorjonen, M.-L., et al. (2009). "A Cross-Linguistic Investigation of the Site of Initiation of Same-Turn SelfRepair," in Conversation Analysis: Comparative Perspectives. Editor J. Sidnell (Cambridge University Press), 60-103.

Fuchs, S., and Rochet-Capellan, A. (2021). The Respiratory Foundations of Spoken Language. Annu. Rev. Linguist. 7, 13-30. doi:10.1146/annurev-linguistics031720-103907

Garfinkel, H. (1967). Studies in Ethnomethodology. Prentice-Hall.

Goffman, E. (1978). Response Cries. Language 54 (4), 787. doi:10.2307/413235

Golato, A. (2000). An innovative German quotative for reporting on embodied actions: Und ich so/und er so 'and i'm like/and he's like'. J. Pragmatics 32 (1), 29-54. doi:10.1016/S0378-2166(99)00030-2

Goodwin, C. (2000). Action and Embodiment within Situated Human Interaction. J. Pragmatics 32 (10), 1489-1522. doi:10.1016/S0378-2166(99)00096-X

Goodwin, C. (1995). Co-Constructing Meaning in Conversations with an Aphasie Man. Res. Lang. Soc. Interaction 28 (3), 233-260. doi:10.1207/s15327973rlsi2803_4
Goodwin, C. (2018). Co-operative Action. Cambridge University Press.

Goodwin, C. (1979). "The Interactive Construction of a Sentence in Natural Conversation," in Everyday Language: Studies in Ethnomethodology. Editor G. Psathas (New York: Irvington Publishers), 97-121.

Goodwin, M. H., and Goodwin, C. (1986). Gesture and Coparticipation in the Activity of Searching for a Word. Semiotica 62 (1-2), 51-76. doi:10.1515/ semi.1986.62.1-2.51

Haddington, P., Keisanen, T., Mondada, L., and Nevile, M. (2014). Multiactivity in Social Interaction: Beyond Multitasking. (John Benjamins).

Hagins, M., and Lamberg, E. M. (2006). Natural Breath Control during Lifting Tasks: Effect of Load. Eur. J. Appl. Physiol. 96 (4), 453-458. doi:10.1007/s00421005-0097-1

Hakulinen, A. (2001). Minimal and Non-minimal Answers to Yes-No Questions. Prag 11 (1), 1-15. doi:10.1075/prag.11.1.01hak

Hammarberg, B. (2000). Voice Research and Clinical Needs. Folia Phoniatr Logop 52, 93-102. doi:10.1159/000021517

Hayashi, M. (2005). Joint Turn Construction through Language and the Body: Notes on Embodiment in Coordinated Participation in Situated Activities. Semiotica 2005 (156), 21-53. doi:10.1515/semi.2005.2005.156.21

Hayashi, M. (2003). Language and the Body as Resources for Collaborative Action: A Study of Word Searches in Japanese Conversation. Res. Lang. Soc. Interaction 36 (2), 109-141. doi:10.1207/S15327973RLSI3602_2

Hayashi, M., and Yoon, K.-E. (2006). A Cross-Linguistic Exploration of Demonstratives in Interaction. Sl 30 (3), 485-540. doi:10.1075/sl.30.3.02hay

Helasvuo, M.-L. (2001). Syntax in the Making: The Emergence of Syntactic Units in Finnish Conversational Discourse. John Benjamins. doi:10.1075/ sidag. 9

Hixon, T. J., Weismer, G., and Hoit, J. D. (2018). Preclinical Speech Science: Anatomy, Physiology, Acoustics, and Perception. Third Edition. San Diego: Plural Publishing.

Hodges, P. W., Eriksson, A. E., Shirley, D., and Gandevia, S. C. (2005). Intraabdominal Pressure Increases Stiffness of the Lumbar Spine. J. Biomech. 38 (9), 1873-1880. doi:10.1016/j.jbiomech.2004.08.016

Hoey, E. M. (2020). When Conversation Lapses: The Public Accountability of Silent Copresence. Oxford University Press. doi:10.1093/oso/ 9780190947651.001.0001

Holt, E. (2007). “"'I'm Eyeing Your Chop up Mind": Reporting and Enacting," in Reporting Talk: Reported Speech in Interaction. Editors E. Holt and R. Clift (Cambridge University Press), 47-80.

Hopper, P. (1987). Emergent Grammar. Bls 13, 139-157. doi:10.3765/ bls.v13i0.1834

Hopper, P. (2011). "Emergent Grammar and Temporality in Interactional Linguistics," in Constructions: Emerging and Emergent. Editors P. Auer and S. Pfänder (Berlin: De Gruyter), 22-44. https://www.degruyter.com/view/title/37335.

Ikeda, E. R., Borg, A., Brown, D., Malouf, J., Showers, K. M., and Li, S. (2009). The Valsalva Maneuver Revisited: The Influence of Voluntary Breathing on Isometric Muscle Strength. J. Strength Conditioning Res./Natl. Strength Conditioning Assoc. 23 (1), 127-132. doi:10.1519/JSC.0b013e31818eb256

Iwasaki, S. (2009). Initiating Interactive Turn Spaces in Japanese Conversation: Local Projection and Collaborative Action. Discourse Process. 46 (2-3), 226-246. doi:10.1080/01638530902728918

Iwasaki, S. (2011). “The Multimodal Mechanics of Collaborative Unit Construction in Japanese Conversation," in Embodied Interaction: Language and Body in the Material World. Editors J. Streeck, C. Goodwin, and C. LeBaron (Cambridge University Press), 106-120.

Kaskan, E. R., and Ho, I. K. (2016). Microaggressions and Female Athletes. Sex Roles 74 (7), 275-287. doi:10.1007/s11199-014-0425-1

Keevallik, L. (2015). "Coordinating the Temporalities of Talk and Dance," in Temporality in Interaction. Editors A. Deppermann and S. Günthner (John Benjamins), 309-336. doi:10.1075/slsi.27.10kee

Keevallik, L. (2013a). "Here in Time and Space: Decomposing Movement in Dance Instruction," in Interaction and Mobility: Language and the Body in Motion. Editors P. Haddington, L. Mondada, and M. Nevile (Berlin: De Gruyter), 345-370.

Keevallik, L. (2013b). The Interdependence of Bodily Demonstrations and Clausal Syntax. Res. Lang. Soc. Interaction 46 (1), 1-21. doi:10.1080/08351813.2013.753710

Keevallik, L. (2018). What Does Embodied Interaction Tell Us about Grammar? Res. Lang. Soc. Interaction 51 (1), 1-21. doi:10.1080/08351813.2018.1413887 
Koshik, I. (2002). Designedly Incomplete Utterances: A Pedagogical Practice for Eliciting Knowledge Displays in Error Correction Sequences. Res. Lang. Soc. Interaction 35 (3), 277-309. doi:10.1207/S15327973RLSI3503_2

Laakso, M., and Klippi, A. (1999). A Closer Look at the 'hint and Guess' Sequences in Aphasic Conversation. Aphasiology 13 (4-5), 345-363. doi:10.1080/ 026870399402136

Lakoff, G., and Johnson, M. (1980). Conceptual Metaphor in Everyday Language. J. Philos. 77 (8), 453-486. doi:10.2307/2025464

Lamberg, E. M., Mateika, J. H., Cherry, L., and Gordon, A. M. (2003). Internal Representations Underlying Respiration during Object Manipulation. Brain Res. 982 (2), 270-279. doi:10.1016/S0006-8993(03)03120-2

Lerner, G. H. (2013). "On the Place of Hesitating in Delicate Formulations: A TurnConstructional Infrastructure for Collaborative Indiscretion," in Conversational Repair and Human Understanding. Editors M. Hayashi, G. Raymond, and J. Sidnell (Cambridge University Press), 95-134.

Lerner, G. H. (2003). Selecting Next Speaker: The Context-Sensitive Operation of a Context-free Organization. Lang. Soc. 32 (2), 177-201. doi:10.1017/ S004740450332202X

$\mathrm{Li}, \mathrm{X}$. (2016). Some Interactional Uses of Syntactically Incomplete Turns in Mandarin Conversation. Cld 7 (2), 237-271. doi:10.1075/cld.7.2.03li

Lieberman, P., and Blumstein, S. E. (1988). Speech Physiology, Speech Perception, and Acoustic Phonetics. Cambridge University Press. doi:10.1017/ cbo9781139165952

Linell, P. (2009). Rethinking Language, Mind, and World Dialogically: Interactional and Contextual Theories of Human Sense-Making. Charlotte: Information Age Publishing.

Linell, P. (2005). The Written Language Bias in Linguistics: Its Nature, Origins and Transformations. Abingdon: Routledge.

Löfgren, A., and Hofstetter, E. (2021). Introversive semiosis in action: Depictions in opera rehearsals. Social Semiotics. doi:10.1080/10350330.2021.1907180

Massery, M., Hagins, M., Stafford, R., Moerchen, V., and Hodges, P. W. (2013). Effect of Airway Control by Glottal Structures on Postural Stability. J. Appl. Physiol. 115 (4), 483-490. doi:10.1152/japplphysiol.01226.2012

Mateika, J. H., and Gordon, A. M. (2000). Adaptive and Dynamic Control of Respiratory and Motor Systems during Object Manipulation. Brain Res. 864 (2), 327-337. doi:10.1016/S0006-8993(00)02221-6

Mazeland, H. (2007). Parenthetical Sequences. J. Pragmatics 39 (10), 1816-1869. doi:10.1016/j.pragma.2007.05.005

Mondada, L. (2014). The Local Constitution of Multimodal Resources for Social Interaction. J. Pragmatics 65, 137-156. doi:10.1016/j.pragma.2014.04.004

Mori, J., and Hayashi, M. (2006). The Achievement of Intersubjectivity through Embodied Completions: A Study of Interactions between First and Second Language Speakers. Appl. Linguistics 27 (2), 195-219. doi:10.1093/applin/aml014

Newmeyer, F. J. (2003). Grammar Is Grammar and Usage Is Usage. Language 79 (4), 682-707. doi:10.1353/lan.2003.0260

Norén, N., Svensson, E., and Telford, J. (2013). Participants' Dynamic Orientation to Folder Navigation when Using a VOCA with a Touch Screen in Talk-InInteraction. Augmentative Altern. Commun. 29 (1), 20-36. doi:10.3109/ 07434618.2013.767555

O'Connell, D. G., Brewer, J. F., Man, T. H., Weldon, J. S., and Hinman, M. R. (2016). The Effects of Forced Exhalation and Inhalation, Grunting, and Valsalva Maneuver on Forehand Force in Collegiate Tennis Players. J. Strength Cond Res. 30 (2), 430-437. doi:10.1519/JSC.0000000000001120

Oelschlaeger, M. L., and Damico, J. S. (1998). Joint Productions as a Conversational Strategy in Aphasia. Clin. Linguistics Phonetics 12 (6), 459-480. doi:10.3109/ 02699209808985238

Olsher, D. (2004). "Talk and Gesture: The Embodied Completion of Sequential Actions in Spoken Interaction," in Second Language Conversations. Editors R. Gardner and J. Wagner (London: Continuum), 221-245.

Parkes, M. J. (2006). Breath-holding and its Breakpoint. Exp. Physiol. 91 (1), 1-15. doi:10.1113/expphysiol.2005.031625

Pehkonen, S. (2020). Response Cries Inviting an Alignment: Finnishhuh Huh. Res. Lang. Soc. Interaction 53 (1), 19-41. doi:10.1080/08351813.2020.1712965

Pekarek Doehler, S., De Stefani, E., and Horlacher, A.-S. (2015). Time and Emergence in Grammar: Disclocation, Topicalization and Hanging Topic in French Talk-In-Interaction. Amsterdam: John Benjamins. doi:10.1075/slsi.28

Pekarek Doehler, S., Maschler, Y., Keevallik, L., and Lindström, J. (2020). "Chapter 1. Complex Syntax-In-Interaction," in Emergent Syntax for Conversation: Clausal Patterns and the Organization of Action. Editors Y. Maschler,
S. Pekarek Doehler, J. Lindström, and L. Keevallik (John Benjamins), 1-22. doi:10.1075/slsi.32.01doe

Perkins, L. (2003). "Negotiating Repair in Aphasic Conversation: Interactional Issues," in Conversation and Brain Damage. Editor C. Goodwin (Oxford University Press), 147-162.

Persson, R. (2017). Fill-in-the-Blank Questions in Interaction: Incomplete Utterances as a Resource for Doing Inquiries. Res. Lang. Soc. Interaction 50 (3), 227-248. doi:10.1080/08351813.2017.1340698

Postma, A. (2000). Detection of Errors during Speech Production: A Review of Speech Monitoring Models. Cognition 77, 97-132. doi:10.1016/s0010-0277(00)00090-1

Radford, A., Atkinson, M., Britain, D., Clahsen, H., and Spencer, A. (2009). Linguistics: An Introduction. 2nd ed. Cambridge University Press. doi:10.1017/CBO9780511841613

Robinson, J. D. (2016). "Accountability in Social Interaction," in Accountability in Social Interaction. Editor J. D. Robinson (Oxford University Press), 1-44. doi:10.1093/acprof:oso/9780190210557.003.0001

Sacks, H. (1992). Lectures on Conversation. Editor G. Jefferson (Oxford: Blackwell).

Sandage, M. J., Connor, N. P., and Pascoe, D. D. (2013). Voice Function Differences Following Resting Breathing versus Submaximal Exercise. J. Voice 27 (5), 572-578. doi:10.1016/j.jvoice.2013.04.001

Schegloff, E. A. (1987). "Recycled Turn Beginnings: A Precise Repair Mechanism in Conversation's Turn-Taking Organization," in Talk and Social Organisation. Editors G. Button and J. R. E. Lee (Clevedon: Multilingual Matters), 70-85.

Schegloff, E. A. (1993). Reflections on Quantification in the Study of Conversation. Res. Lang. Soc. Interaction 26 (1), 99-128. doi:10.1207/s15327973rlsi2601_5

Schegloff, E. A. (2007). Sequence Organization in Interaction: A Primer in Conversation Analysis I. Cambridge University Press. doi:10.1017/ cbo9780511791208

Schegloff, E. A. (1996). "Turn Organization: One Intersection of Grammar and Interaction," in Interaction and Grammar. Editors E. Ochs, E. A. Schegloff, and S. A. Thompson (Cambridge University Press), 52-133. doi:10.1017/ cbo9780511620874.002

Selting, M. (2001). "Fragments of Units as Deviant Cases of Unit Production in Conversational Talk," in Studies in Interactional Linguistics. Editors M. Selting and E. Couper-Kuhlen (John Benjamins Publishing), 229-258. doi:10.1075/ sidag.10.12sel

Sidnell, J. (2006a). "Repair," in Handbook of Pragmatics. Editor J. Verschueren (John Benjamins).

Sidnell, J. (2006b). Coordinating Gesture, Talk, and Gaze in Reenactments. Res. Lang. Soc. Interaction 39 (4), 377-409. doi:10.1207/s15327973rlsi3904_2

Thompson, S. A., and Couper-Kuhlen, E. (2005). The Clause as a Locus of Grammar and Interaction. Discourse Stud. 7 (4-5), 481-505. doi:10.1177/ 1461445605054403

Trouvain, J., and Truong, K. P. (2015). Prosodic Characteristics of Read Speech before and after Treadmill Running, 3700-3704.

Welch, A. S., and Tschampl, M. (2012). Something to Shout about: A Simple, Quick Performance Enhancement Technique Improved Strength in Both Experts and Novices. J. Appl. Sport Psychol. 24 (4), 418-428. doi:10.1080/10413200.2012.688787

Wilkinson, R., and Morris, S. (2020). "My Own Space in This World': Stammering, Telephone Calls, and the Progressivity and Permeability of Turns-At-Talk," in Atypical Interaction: The Impact of Communicative Impairments within Everyday Talk. Editors R. Wilkinson, J. P. Rae, and G. Rasmussen (Springer International Publishing), 319-344. doi:10.1007/ 978-3-030-28799-3_11

Wilkinson, S., and Weatherall, A. (2011). Insertion Repair. Res. Lang. Soc. Interaction 44 (1), 65-91. doi:10.1080/08351813.2011.544136

Conflict of Interest: The authors declare that the research was conducted in the absence of any commercial or financial relationships that could be construed as a potential conflict of interest.

Copyright $\odot 2021$ Hofstetter, Keevallik and Löfgren. This is an open-access article distributed under the terms of the Creative Commons Attribution License (CC BY). The use, distribution or reproduction in other forums is permitted, provided the original author(s) and the copyright owner(s) are credited and that the original publication in this journal is cited, in accordance with accepted academic practice. No use, distribution or reproduction is permitted which does not comply with these terms. 